\title{
EVALUATION OF GRINDING WHEEL WEAR WHEN GRINDING VACO 180 STEEL UNDER VARIABLE GRINDING CONDITIONS
}

\author{
Jindřich Farský, Tomáš Bakša, Miroslav Zetek, Pavel Adámek
}
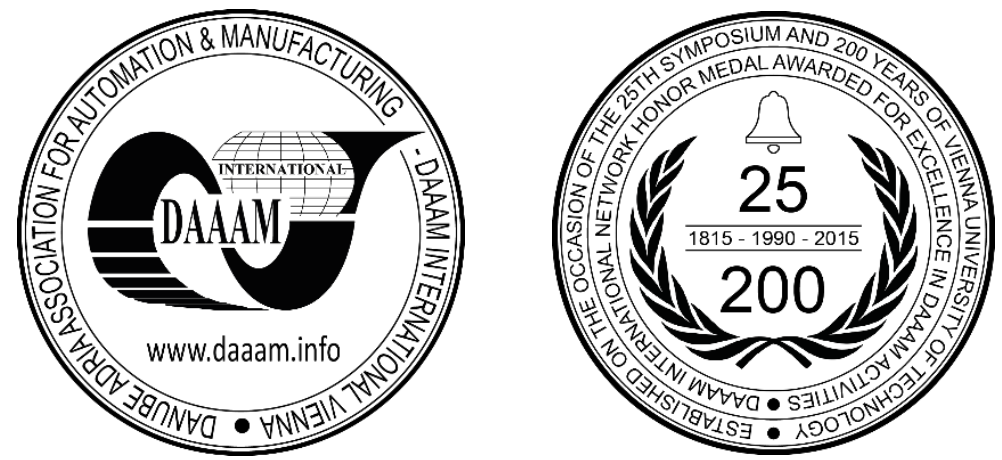

This Publication has to be referred as: Farsky, J[indrich]; Baksa, T[omas]; Zetek, M[iroslav] \& Adamek, P[avel] (2018). Evaluation of Grinding Wheel Wear when Grinding VACO 180 Steel under Variable Grinding Conditions, Proceedings of the 29th DAAAM International Symposium, pp.0772-0776, B. Katalinic (Ed.), Published by DAAAM International, ISBN 978-3-902734-20-4, ISSN 1726-9679, Vienna, Austria

DOI: $10.2507 / 29$ th.daaam.proceedings.112

\begin{abstract}
This work is focused on the size of the grinding wheel wear when grinding maraging steel VACO 180 with variable grinding parameters such as grinding speed and depth of cut. Maraging steel VACO 180 is a company marking for steel very similar to 1.2709 or DIN X3NiCoMo 189 5. Typical fields of application for this steel are in mechanically stressed tools. Two different grinding wheels with $\mathrm{SiC}$ abrasives were used for grinding. Grinding wheel wear is a very important value because this value can influence the future state of the surface of a component, especially the dimensions of the component. Besides, the size of wear can show us if the grinding conditions were correctly selected. Therefore, it is very important to monitor this.
\end{abstract}

Keywords: Grinding; Grinding wheels; SiC; Wear; Grinding parameters

\section{Introduction}

$\mathrm{SiC}$ grinding wheels with ceramic binder are conventional grinding wheels. These types of grinding wheels are subject to normal wear by grinding. The wear of grinding wheels is a very important factor, because the size of wear can influence the future of the ground surface and the life of the grinding wheel. [1] Moreover, the size of wear on the grinding wheel can predict if the selected grinding conditions are good or bad. The grinding conditions greatly influence the size of wear of the grinding wheel. This factor can be seen in Fig. 1. and Fig. 2., where the grinding speed and depth of cut greatly influence wear either positively or negatively.[2] Of course, the cutting conditions are also affected by other grinding parameters such as forces, temperature, accuracy, roughness and so on which are very important because the grinding is a finishing process from which excellent surface quality and very high accuracy is expected. [3], [4]

The aim of this work is to investigate the influence of grinding conditions, especially grinding speed and depth of cut, on the wear of a grinding wheel when grinding maraging steel VACO 180 with two different grinding wheels with SiC abrasive and ceramic binder. The amount of wear on the grinding wheel under different grinding conditions was evaluated. Wear on the grinding wheel is measured as a change to its diameter after each experiment. The results of these experiments verify the change of wear on the grinding wheels when grinding maraging steel VACO 180 with a low grinding speed. [5], [6], [7] 
Input parameters

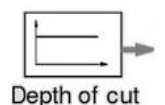

Workpiece speed

Spec. material removal

Fig. 1. Influence of grinding speed on wear [2]

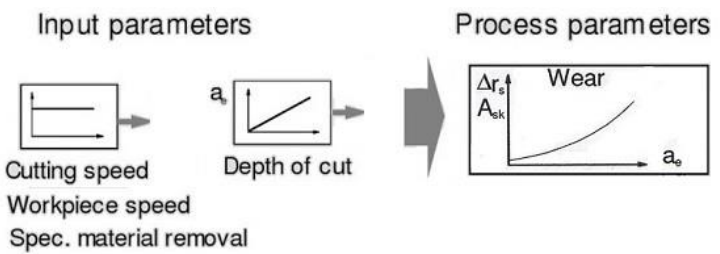

Fig. 2. Influence of depth of cut on wear [2]

\section{Material and equipment}

As mentioned in the introduction, the material of the test bar is maraging steel VACO 180 which is very similar to 1.2709 or DIN X3NiCoMo 1895 . This type of material is used for high stressed tools, because it is high strength curable maraging steel, which has an optimal combination of high tensile strength and toughness. The basic chemical composition of this material is shown in Table 1. Table 2. shows the mechanical properties of this material. [8]

\begin{tabular}{|c|c|c|c|c|c|}
\hline $\mathbf{C}$ & $\mathbf{C o}$ & $\mathbf{M o}$ & $\mathbf{N i}$ & $\mathbf{T i}$ & Other \\
\hline$<0.03 \%$ & $9.0 \%$ & $5.0 \%$ & $18.5 \%$ & $0.75 \%$ & $\mathrm{Al}, \mathrm{B}, \mathrm{Zr}$ \\
\hline
\end{tabular}

Table 1. Chemical composition of maraging steel VACO 180 [8]

\begin{tabular}{|c|c|c|c|c|c|}
\hline Yield strength & $\begin{array}{c}\text { Tensile } \\
\text { strength }\end{array}$ & Ductility & Contraction & $\begin{array}{c}\text { Notch } \\
\text { toughness }\end{array}$ & Hardness \\
\hline $640 \mathrm{MPa}$ & $930-1130 \mathrm{MPa}$ & $12 \%$ & $60 \%$ & $55 \mathrm{~J}$ & $350 \mathrm{HV}$ \\
\hline
\end{tabular}

Table 2. Mechanical properties of maraging steel VACO 180 in annealed condition [8]

The test bars shown in Fig. 3 were made from VACO 180. The basic dimensions of this bar are $180 \times 36 \times 5.2 \mathrm{~mm}$ (length $\mathrm{x}$ height $\mathrm{x}$ width). These test bars were clamped in a special clamping mechanism for the ANCA MX7 because this grinder allows clamping of only cylindrical shapes.

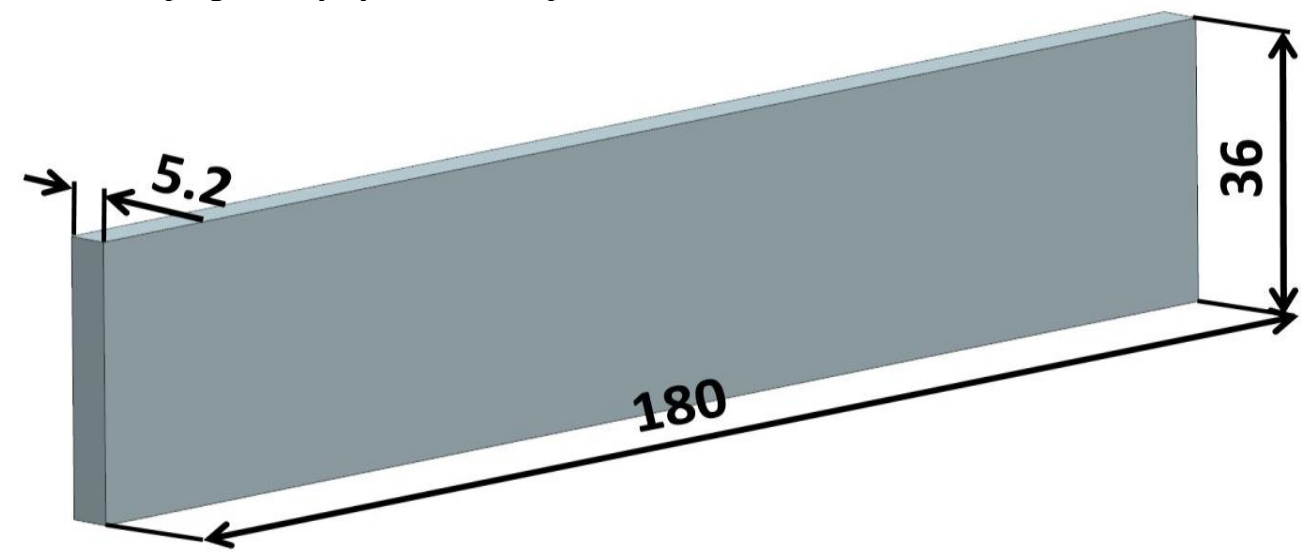

Fig. 3. Basic dimension of the test bar

Two different grinding wheels were selected to grind this material, with the same types of abrasive grains and binder. The abrasive grains are SiC (silicon carbide) which are connected by a ceramic binder. Detailed information about the composition of this grinding wheel is shown in Table 3., where there are listed designation, specifications, shapes, dimensions and so on.

\begin{tabular}{|c|c|c|c|c|c|c|c|}
\hline Designation & Shape & Dimension & $\begin{array}{c}\text { Type of } \\
\text { grain }\end{array}$ & $\begin{array}{c}\text { Grain size } \\
\text { [FEPA] }\end{array}$ & Binder & Hardness & Specification \\
\hline SiC 01 - VS & $1 \mathrm{~A} 1$ & $100 \times 6$ & $\begin{array}{c}\text { Silicon } \\
\text { carbide green }\end{array}$ & $\begin{array}{l}220 \text { (very } \\
\text { soft) }\end{array}$ & Ceramic & Medium & $\begin{array}{c}49 \mathrm{C} 220 \mathrm{~K} 9 \\
\mathrm{~V} 40\end{array}$ \\
\hline $\mathrm{SiC} 02-\mathrm{S}$ & $1 \mathrm{~A} 1$ & $117 \times 10$ & $\begin{array}{c}\text { Silicon } \\
\text { carbide green }\end{array}$ & 80 (soft) & Ceramic & Hard & SC $80-8-\mathrm{V}$ \\
\hline
\end{tabular}

Table 3. Specifications of grinding wheels for experiments 


\section{Experiment}

The experiment was designed to measure the wear on the grinding wheels, therefore it was necessary to specify the grinding parameters, grinding strategy and measurement on the measuring machine. The Zoller Genius $3 \mathrm{~s}$ was selected to measure the wear on the grinding wheels and it can scan the profile of the grinding wheels and make images of the surface.

The grinding speed and the depth of cut were selected as variables for the experiment. The grinding speed values selected from lower values of speeds. An overview of all the experiments is shown in Table 4. with the designation and values of grinding speed $v_{c}$ and depth of cut $a_{e}$. The feed rate was constant with a value of $200 \mathrm{~mm} \cdot \mathrm{min}^{-1}$.

\begin{tabular}{|c|c|c|c|c|c|c|c|c|}
\hline Designation & $\mathrm{Vc}\left[\mathrm{m} . \mathrm{s}^{-1}\right]$ & $\mathrm{ae}_{\mathrm{e}}[\mathrm{mm}]$ & Designation & $\mathrm{vc}_{\mathrm{c}}\left[\mathrm{m}_{\mathrm{.}} \mathrm{s}^{-1}\right]$ & $\mathbf{a e}_{\mathrm{e}}[\mathrm{mm}]$ & Designation & $\mathrm{vc}_{\mathrm{c}}\left[\mathrm{m} \cdot \mathrm{s}^{-1}\right]$ & $\mathrm{ae}_{\mathrm{e}}[\mathrm{mm}]$ \\
\hline Exp01 & 10 & 0.05 & Exp04 & 10 & 0.1 & Exp07 & 10 & 0.2 \\
\hline Exp02 & 15 & 0.05 & Exp05 & 15 & 0.1 & Exp08 & 15 & 0.2 \\
\hline Exp03 & 20 & 0.05 & Exp06 & 20 & 0.1 & Exp09 & 20 & 0.2 \\
\hline
\end{tabular}

Table 4. Variables from grinding conditions

Down grinding was proposed as the grinding strategy. This means that the grinding wheel rotates in the same direction as the movement of the test bar. It was also necessary to select the length of grinding, which was $540 \mathrm{~mm}$. This means that each grinding path must be repeated 3 times. Once the grinding length has been reached, the experiment is finished. The grinding strategy is shown in

Fig. 4. The wear on the grinding wheel was measured after each experiment. Also, it was necessary to recover the grinding wheel with a special grinding stone. This recovering is very important to eliminate errors in the next experiments.

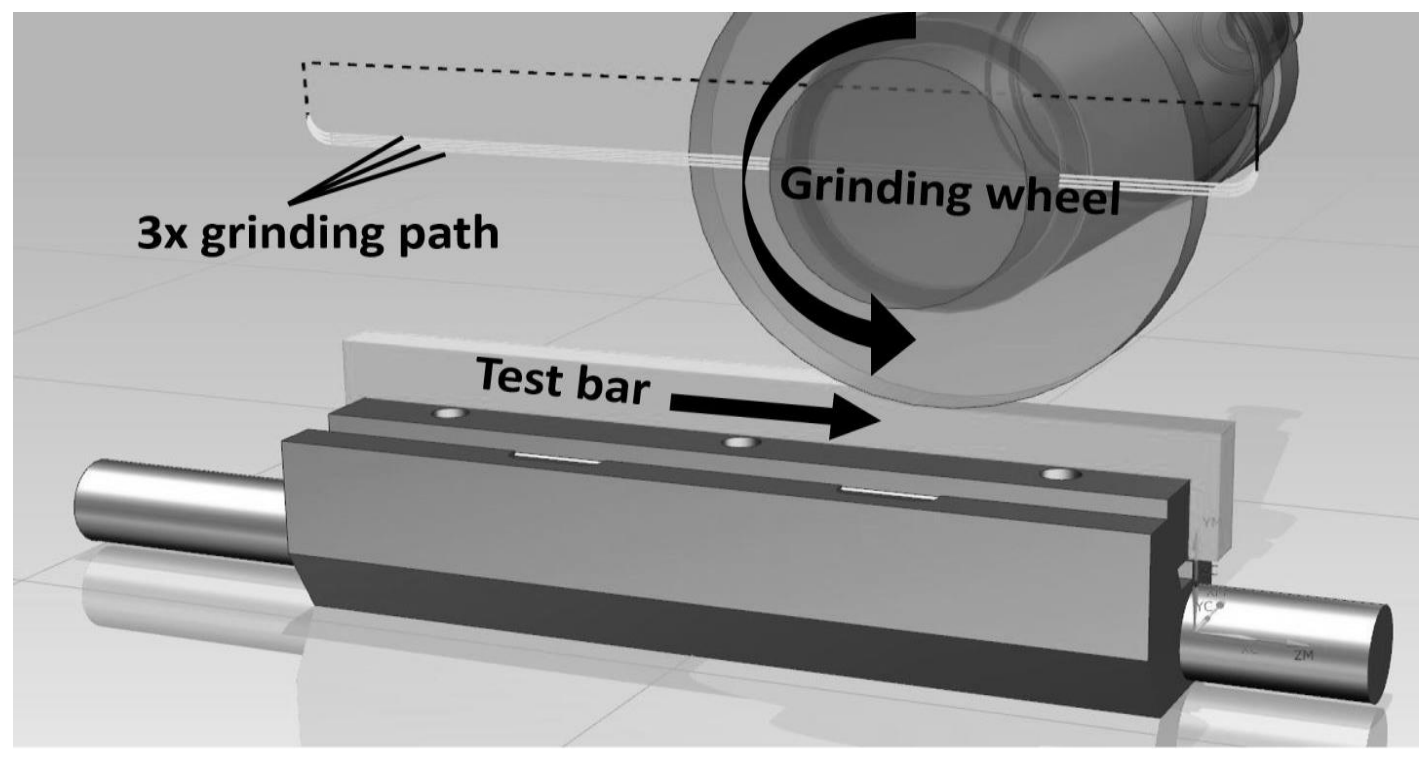

Fig. 4. The strategy used for experiments

\section{Results}

The main idea of this experiment is to verify the influence of the grinding conditions on the size of wear on the grinding wheels. The evaluation was performed by scanning the grinding wheel profile and measuring the differences between each experiment. These measurements were entered into graphs for each grinding wheel. The values of wear on the grinding wheel SiC 01 - VS shown in Graph 1., where you can see the changing values of wear. The maximum value was achieved in experiment 7 with a value of $0.272 \mathrm{~mm}$ per diameter of grinding wheel, but this value was with an error because the grinding wheel was damaged, therefore the experiment had to be stopped after the first grinding path. Therefore the maximum value is reached in experiment 4. But for practical purposes, the values which have the minimum value are more important. The minimum value was obtained in experiment 6 which had a grinding speed of $20 \mathrm{~m} . \mathrm{s}^{-1}$ and depth of cut $0.1 \mathrm{~mm}$.

The values of wear measured for the second grinding wheel SiC $02-\mathrm{S}$ are shown in Graph 2., where the maximum value was obtained in experiment 01 , which is $0.105 \mathrm{~mm}$ diameter. The minimum value obtained is in experiment 02 which has a value of $0.008 \mathrm{~mm}$ diameter with a grinding speed of $15 \mathrm{~m} . \mathrm{s}^{-1}$ and depth of cut $0.05 \mathrm{~mm}$. As you can see on the graph, experiment no. 7 for grinding wheel $\mathrm{SiC} 02-\mathrm{S}$ is not marked here. This was because the grinding wheel came loose during the experiment, meaning the experiment had to been abandoned and the measurements were not made. 


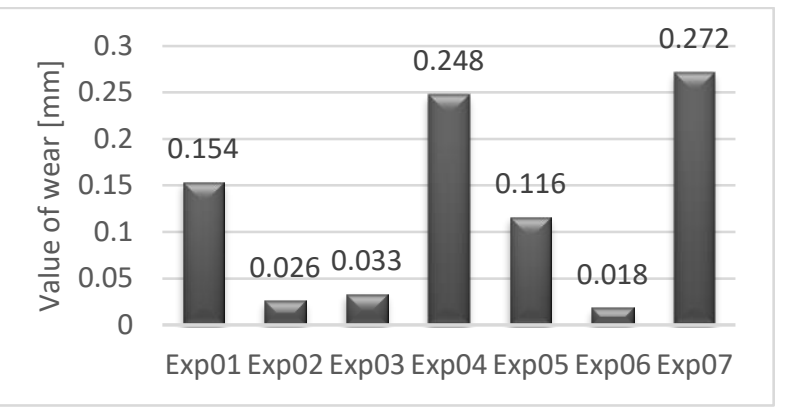

Graph 1. Wear of grinding wheel SiC 01 - VS

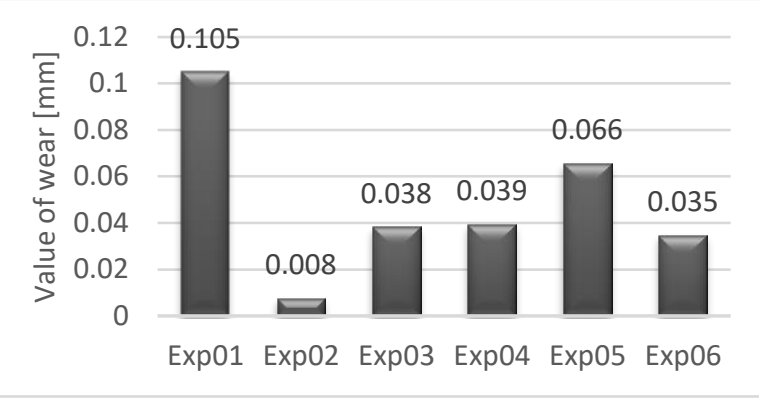

Graph 2. Wear of grinding wheel SiC $02-\mathrm{S}$

Graph 3. gives a better view of the differences between the grinding wheels. Firstly, it is possible to say the grinding wheel $\mathrm{SiC} 02-\mathrm{S}$ has better resistance to wear because in only two experiments the value of wear is bigger than on the first grinding wheel. One of the reasons why the second wheel has less wear is the different structure, which is better for grinding this material when using these grinding conditions.

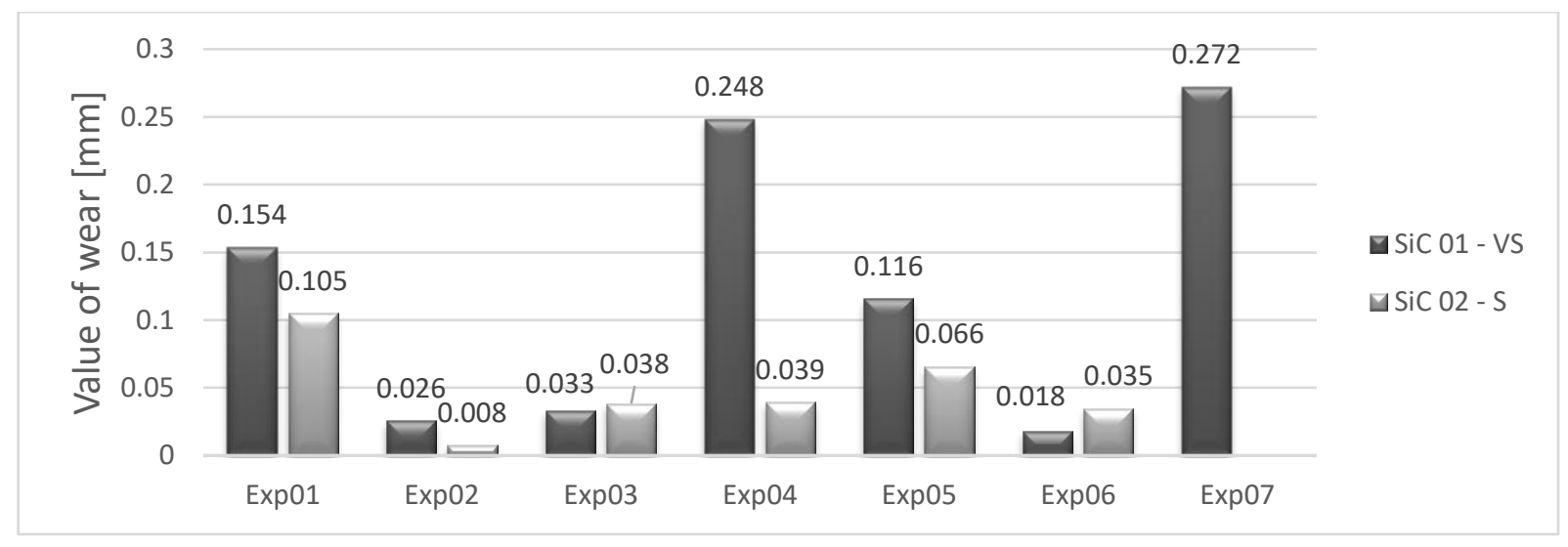

Graph 3. Comparison of wear on the grinding wheels

The values of wear for experiments no. 9 and 8 are not mentioned here, because they were abandoned. The surface of the test bars burned after the first grinding path, and also the material from the test bar clogged the space between the abrasive grains as shown in the photographs below. Here you can see the difference between the new grinding wheels and the clogged wheels.

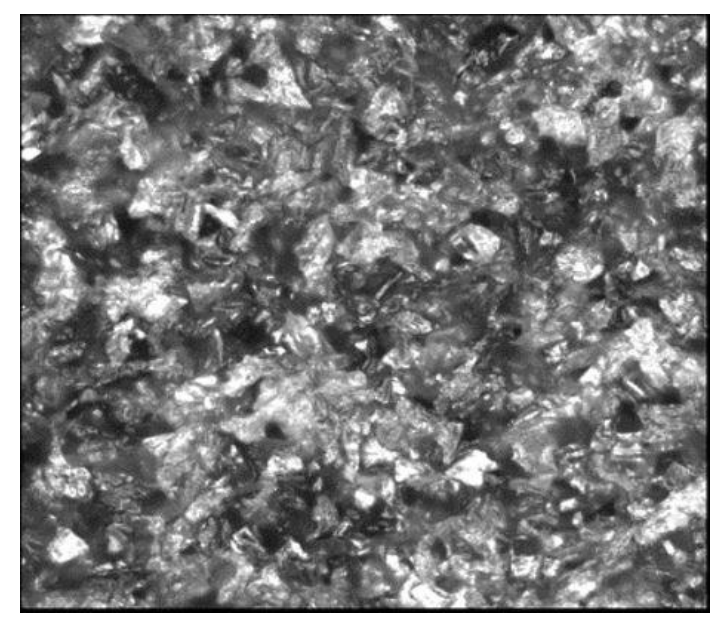

Fig. 5. The structure of new grinding wheel SiC $01-$ VS

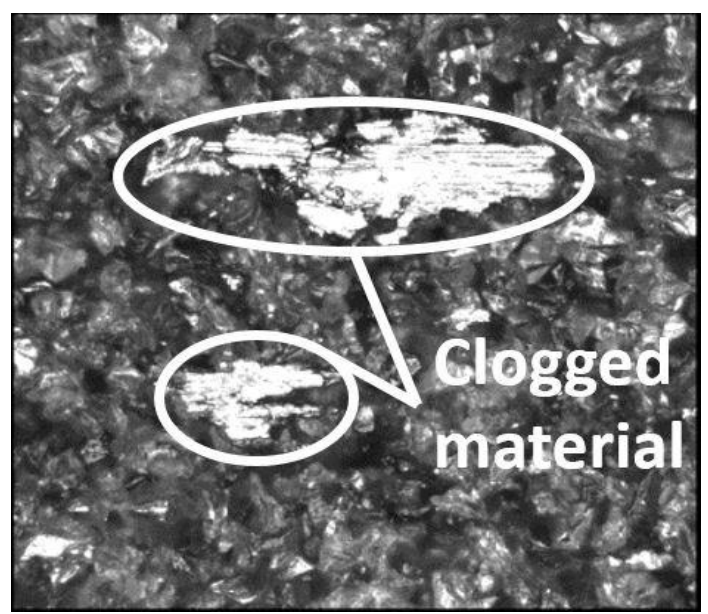

Fig. 6. The clogged structure of grinding wheel $\mathrm{SiC} 01-$ VS 


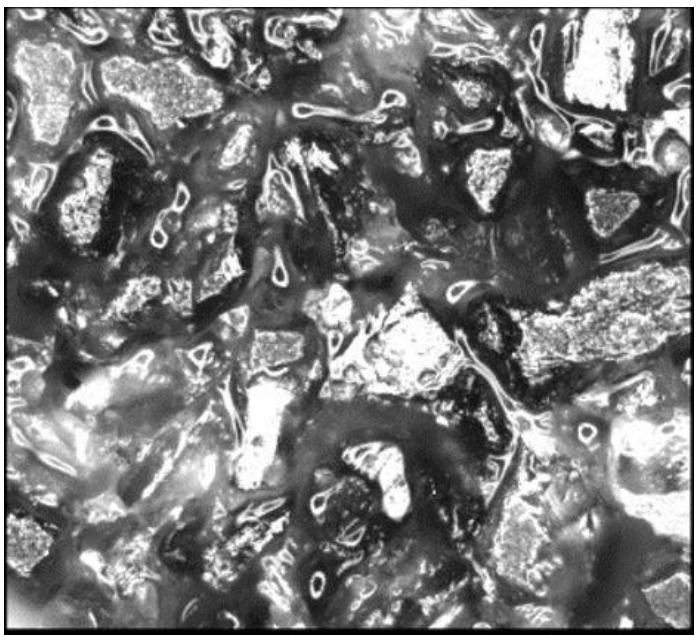

Fig. 7. The structure of new grinding wheel $\mathrm{SiC} 02-\mathrm{S}$

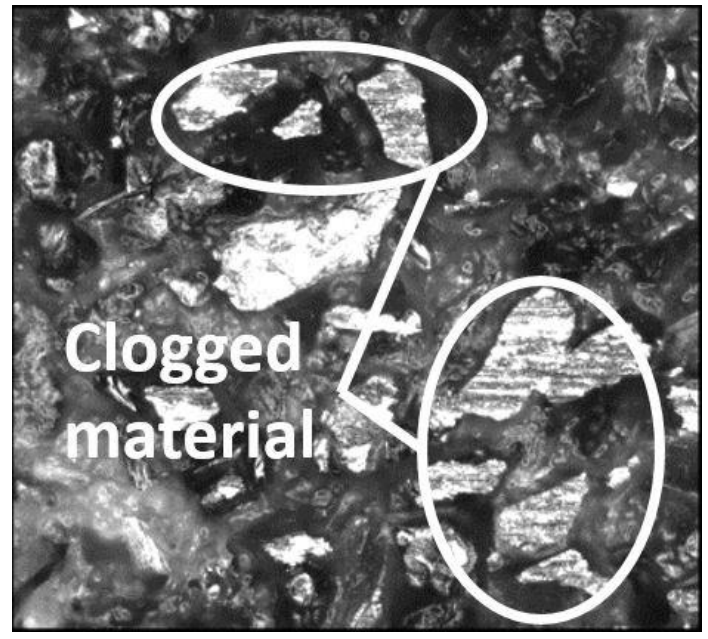

Fig. 8. The clogged structure of grinding wheel $\mathrm{SiC} 02-$ $\mathrm{S}$

\section{Conclusion}

This article focused on the changing wear on the grinding wheels when grinding test bars from the material VACO 180. The experiment was designed to investigate the influence of the grinding conditions on the wear for two grinding wheels with $\mathrm{SiC}$ abrasive grains and ceramic binder. The grinding speed and depth of cut were selected as variables. From the results it is evident that the grinding wheel marked $\mathrm{SiC} 02-\mathrm{S}$, which has bigger grains and hardness, has the highest resistance to wear under these grinding conditions. Also, the depth of cut of $0.2 \mathrm{~mm}$ was problematic. The experiments with this depth had to been cancelled because the surface or the grinding wheel was damaged or could be damaged by continuing with these conditions. The lowest value of wear on the grinding wheel was measured in experiment no. 2 for grinding wheel $\mathrm{SiC} 02-\mathrm{S}$ which was $0.008 \mathrm{~mm}$.

This research provides basic information about the wear of grinding wheels arising from grinding under different grinding conditions. From the results, it is obvious that it is necessary to focus on the size of wear on the grinding wheel, because by selecting the right grinding conditions we can influence the future life of the grinding wheels.

\section{Acknowledgments}

This article has been prepared under project LO1502 'Development of the Regional Technological Institute' under the auspices of the National Sustainability Programme I of the Ministry of Education of the Czech Republic aimed to support research, experimental development and innovation.

\section{References}

[1] Prinz, S.; Trauth, D.; Mattfeld, P. \& Klocke, F. (2018). 'Influence of different grinding wheel and dressing roller specifications on grinding wheel wear', Prod. Eng. Res. Devel., ISBN 1863-7353, vol. 12, no. 3, pp. 441-448.

[2] Klocke, F. (2009) Manufacturing Processes 2: Grinding, Honing, Lapping. Springer Science \& Business Media ISBN 978-3-540-92259-9.

[3] Li, Z.; Zhang, F.; Zhang, Y. \& Luo, X. (2017). 'Experimental investigation on the surface and subsurface damages characteristics and formation mechanisms in ultra-precision grinding of $\mathrm{SiC}^{\mathrm{C}}$, The International Journal of Advanced Manufacturing Technology, ISSN 1433-3015, vol. 92, no. 5, pp. 2677-2688.

[4] Baksa, T.; Hronek, O.; Farsky, J. \& Zetek, M. (2017). 'Influence of cutting conditions on the surface quality and grinding wheel wear during cylindrical grinding of inconel 718', presented at the Annals of DAAAM and Proceedings of the International DAAAM Symposium, ISBN 978-390273411-2 pp. 500-505.

[5] Liu, L. \& Zhang, F. (2017). 'Prediction model of form error influenced by grinding wheel wear in grinding process of large-scale aspheric surface with $\mathrm{SiC}$ ceramics', The International Journal of Advanced Manufacturing Technology, ISSN 1433-3015, vol. 88, no. 1, pp. 899-906.

[6] Fritsche, A. \& Bleicher, F. (2015). 'Experimental Investigation of the Heat Flux Distribution in Grinding of Titanium Alloy', 25th DAAAM International Symposium on Intelligent Manufacturing and Automation, ISSN 1877-7058, pp. 987-993.

[7] Jianbo, D.; Honghua, S.; Hao, H.; Tengfei, Y.; Wenbo, Z.; Wenfeng, D.; Shijun, J. \& Yihao, Z. (2017). 'The influence of grain geometry and wear conditions on the material removal mechanism in silicon carbide grinding with single grain', Ceramics International, ISSN 0272-8842, vol. 43, pp. 11973-11980.

[8] Bolzano, 'DataSheet of maraging steel X3NiCoMo 18 9 5', Bolzano. [Online]. Available: https://www.bolzano.cz/assets/files/materialove_listy/Vaco\%20180(1).pdf. 